\title{
In vitro comparison of simple tretinoin-cream and cream loaded with tretinoin-SLN
}

\author{
Saman Ahmad Nasrollahi ${ }^{1,2}$, Ali Reza Abbasian ${ }^{1}$ and Effat Sadat Farboud ${ }^{1 *}$ \\ *Correspondence: farbod@tums.ac.ir \\ 'Department of Pharmaceutics, School of Pharmacy, Tehran University of Medical Sciences, Tehran, Iran. \\ ${ }^{2}$ Center for Research \& Training in Skin Diseases \& Leprosy, Tehran University of Medical Sciences, Tehran, Iran.
}

\begin{abstract}
Background: Tretinoin is one of the commonly used medications in treatment of skin aging symptoms. However, its topical application leads to local irritation at the application site which often limits its tolerability by patients. Solid lipid nanoparticles (SLN) have been developed as an alternative carrier system to emulsions with several advantages such as possibility of controlled drug release, drug targeting and increased drug stability.

Methods: In this study, we formulated SLN with hot high pressure homogenization technique. For all formulations the lipid phase was dispersed in water containing 1- $3 \%$ nonionic surfactant at $75^{\circ} \mathrm{C}$ and a premix was formed by homogenizing in an IKA Ultra Turrax high-speed stirrer followed by an IKA high pressure homogenizer. We applied 3, 5, 7 and 9 cycles at pressure range of 250-1000 bars. The z-average and zeta potential was analyzed by Malvern Zetasizer ZEN 3600.

Results: The property of the particles depends on the amount of surfactant, production pressure and the number of homogenization cycles. The best formulation which was stable for two years contained $10 \%$ cetyl palmitate as a lipid, $2 \%$ tego care 450 as a surfactant and $88 \%$ water at 1000 bars (5 cycles) with $\mathrm{z}$-average of $140 \pm 5 \mathrm{~nm}$.

Conclusion: The in vitro release studies showed that SLN containing tretinoin has prolonged profile as compared to commercially available tretinoin creams. It appears that the prolong release profile sustains permeation and absorption of tretinoin and also provides skin tolerability.
\end{abstract}

Keywords: Tretinoin, solid lipid nanoparticles, high pressure homogenizer, photon correlation spectroscopy

\section{Background}

Tretinoin (retinoic acid) has a variety of physiological effects such as regulation of epithelial cell growth and differentiation [1], production of sebum and dermis proteins synthesis $[2,3]$. It has been increasingly at the center of attention because of its efficiency in the topical healing of acne vulgaris, ichtyoses, psoriasis, and neoplasia $[4,5]$.

The commercial topical dosage forms of tretinoin have limited tolerability by consumers be cause they frequently lead to local side effects such as irritation, erythema, peeling and burning at the application site and enhance vulnerability to UV radiation $[6,7]$.

Various drug delivery systems such as liposomes $[8,9]$, niosomes [10] and inclusion complexes were designed to improve side effects related to topical delivery of tretinoin [11].

Solid lipid nanoparticles (SLN) were developed as a substitute of emulsions, liposomes and polymeric nanoparticles. SLNs are aqueous medium, containing solid lipid dispersed particles which stabilized with surfactant layer. The mean particle size (Z-average) of SLN is between 40 to $1000 \mathrm{~nm}[12,13]$. SLN formed from biodegradable lipids may have potentially broad range of application (dermal, oral and intravenous). The SLN production is relatively simple which could be easily scaled up to an industrial production level, and its formulation process does not need any organic solvent [14-16]. Other advantages of SLN include improved physical stability [17], low cost compared to liposomes [18], drug targeting [19], follicular delivery [20], controlled drug delivery [17] and photostability improvement of active pharmaceutical ingredients [21].

In this study we designed the solid lipid nanoparticles and investigated the features of these particles using Photon Correlation Spectroscopy (PCS), Differential Scanning Calorimetry (DSC) and Transmission electron microscopy (TEM). We analyzed stability of SLN and also tested the delivery efficiency of these nanoparticles with franz diffusion cells. Our results suggest the SLN as a useful drug delivery system for controlled release of tretinoin.

\section{Experimentals}

Tretinoin (powder) was a gift from Roche (Basel, Switzerland). Tego Care 450 (Polyglycerolmethylglucosedistearate) was obtained by Goldschmidt (Germany). Compritol 888 ATO was obtained from Croda (France). Cetyl palmitate (CP), Tween 80, Tween 20, Cetyl alcohol, Stearyl alcohol, Isopropyl myristate, Stearic acid (Octadecanoic acid), Span 60 (Sorbitan monostearate), Isopropyl alcohol (Isopropanol) were purchased from Merck (Germany). Tretinoin \%0.05 creams (Pars Daru Pharmaceutical Co. Iran) 
and Retin- $\mathrm{A}^{\oplus} \% 0.05$ creams (Switzerland) were purchased from local pharmacies. Deionized water was prepared freshly whenever required.

\section{Preparation of SLN}

SLN was formulated with nonionic surfactant and hot high pressure homogenization technique. Briefly, $10 \%$ cetyl palmitate as a lipid and $2 \%$ Tego care 450 as a nonionic surfactant were mixed and melted at $75^{\circ} \mathrm{C}$. The hot lipid phase was dispersed in $88 \%$ water at $75^{\circ} \mathrm{C}$ and a premix was formed using a homogenizer (IKA, Ultra Turrax T25) for $1 \mathrm{~min}$ at $8000 \mathrm{rpm}$. The premix was passed through a High Pressure Homogenizer (IKA, LABOR PILOT, Germany). The cycles varied between $3,5,7$ and 9 times in a pressure range of 250-1000 bar [22]. The preparation process was exactly repeated to make tretinoin SLN.

\section{Preparation of base cream}

To prepare base cream, we used a lipid phase containing $15 \%$ isopropyl myristate, $1 \%$ Cetyl palmitate, $1 \%$ Stearyl alcohol, $7 \%$ Cetyl alcohol, and $1.5 \%$ Span 60 as well as an aqueous phase composed of 3.5\% Tween 80 and $71 \%$ distilled water. Both the lipid and aqueous phases of the cosmetic cream were separately heated to $75^{\circ} \mathrm{C}$ and then the hot water phase added to the lipid phase under stirring (IKA, Germany) at $600 \mathrm{rpm}$. Finally, oil / water cream temperature was brought down to $40^{\circ} \mathrm{C}$ and the SLN containing $0.02 \%$ tretinoin, in a ratio of $50-50$ was added to it continuous stirring until it was further cooled down to the room temperature [23]. The final concentration of tretinoin was $0.01 \%$.

\section{Particle size and zeta potential measurements} Photon correlation spectroscopy (PCS) (Malvern Zetasizer ZEN 3600) was used to determine properties of particles such as $z$-average, size distribution (Polydispersity Index $\mathrm{PI}$ ) and zeta potential. The samples were diluted in ratio of 1:20 with deionized water to ensure that the light scattering intensity was within the instrument's sensitivity range. All results correspond to the average \pm SD of three separate experiments at $25^{\circ} \mathrm{C}$.

\section{Stability study}

The physical stability of the best formulation during prolonged storage (at $25^{\circ} \mathrm{C}$ and $20 \%$ humidity) was determined by monitoring changes in zeta potential, particle size and appearance.

\section{Transmission electron microscopy (TEM)}

Transmission electron microscopy (Philips CM120, Netherlands) was conducted using one drop of nanoparticulate dispersion on the carbon-coated copper grid, dried for 3 to 5 minutes, and drained on the filter paper. The grid was further dried by keeping it in the Petri plate, then it was loaded in the transmission electron microscope, and areas were scanned for observation of nanoparticles.

\section{Determination of entrapment efficiency (EE)}

The entrapment efficiency (E.E.) of tretinoin into SLN was determined by separation using Sephadex-G50 column $(13.5 \mathrm{~cm} \times 2.0 \mathrm{~cm})$, washing with distilled water at a flow rate of $2.0 \mathrm{ml} / \mathrm{min}$ [24]. The entrapped and free tretinoin was respectively collected at continuous volume intervals of $2.0 \mathrm{ml}$. The collected samples were diluted using a mixed solvent of methanol and chloroform (1:2). EE was calculated according to the following equation:

$$
\mathrm{EE}=\frac{\text { the amount of entrapped druginSLN }}{\text { the amount of entrapped drug in SLN and free drug in dispersion }}
$$

\section{Differential Scanning Calorimetry (DSC)}

Calorimetry studies were performed by DSC instrument (Mettle Toledo DSC823, Switzerland). Measurements were carried out on the simple SLN, tretinoin-loaded SLN (both as lyophilized powder forms), tretinoin, Tego care 450 and cetyl palmitate as a lipid phase in SLN formulation and an empty standard aluminum pan was used as reference. 1-2 $\mathrm{mg}$ of samples was accurately weighted in $40 \mu$ aluminum pans and DSC spectrum was recorded at a heating rate of $5 \mathrm{~K} / \mathrm{min}$ from $25^{\circ} \mathrm{C}$ to $200^{\circ} \mathrm{C}$. Each experiment was done in triplicate.

\section{In vitro release studies}

In vitro release of tretinoin from different formulation was evaluated by using cellulose nitrate membrane $(0.45$ micron). The membrane was mounted on modified Franz diffusion cells with a surface of $12.56 \mathrm{Cm}^{2}$ and a receptor volume of $42 \mathrm{ml}$. Tretinoin is freely soluble in isopropyl alcohol so it was chosen as the receptor fluid. Then, $0.5 \mathrm{~g}$ of the formulations was applied with a curved spatula in the donor compartment and the diffusion cells covered with an aluminum foil to prevent light exposure. The temperature was maintained at $37.0 \pm 1^{\circ} \mathrm{C}$ by water jacket. Sampling was done at 10, 20, 30, 60, 120, 180, 240, 300, 360,420 and $480 \mathrm{~min}$. and at each point, $3.0 \mathrm{ml}$ aliquots were drawn from the receiver compartment. After that, an equivalent volume of receptor fluid was put back to the receiver compartment to keep sink condition. The profile of release was then plotted.

\section{In vitro skin permeation studies}

In vitro skin permeation studies were done by excised male rat skin (preapproved and carried out according to the Ethical Committee of the Animal Care and Use Guidelines of the Tehran University of Medical sciences). Immediately after excision the subcutaneous fatty tissue was removed using a scalpel. The skin was cut and stored in phosphate buffer solution $(\mathrm{pH}=7.4)$ at $4^{\circ} \mathrm{C}$ until use. The maximum storage time was $12 \mathrm{~h}$.

The rat skin was mounted on modified Franz diffusion 
Nasrollahi et al. Journal of Pharmaceutical Technology \& Drug Research 2013, http://www.hoajonline.com/journals/pdf/2050-120X-2-13.pdf

Table 1. The effect of changing surfactant percentage and pressure on particle size, zeta potentials and poly dispersibility index (Pd.I) of formulations. In this chart $\mathrm{O}=$ oil, $\mathrm{W}=$ water and $\mathrm{S}=$ surfactant.

\begin{tabular}{|c|c|c|c|c|c|c|c|c|}
\hline Name of formulations & $\mathrm{O} \%$ & W\% & S\% & $\begin{array}{c}\text { Homogenization } \\
\text { Pressure (bar) }\end{array}$ & $\begin{array}{c}\text { Number of homogenization } \\
\text { cycles }\end{array}$ & $\begin{array}{c}\text { Z-Average } \\
(\mathbf{n m})\end{array}$ & Pd.I & Zeta Potential (mv) \\
\hline SLN1 & 10 & 89 & 1 & 250 & 5 & $227 \pm 7.5$ & $0.203 \pm 0.016$ & $-50.5 \pm 2.3$ \\
\hline SLN2 & 10 & 89 & 1 & 500 & 5 & $204 \pm 4.7$ & $0.198 \pm 0.014$ & $-49.2 \pm 1.8$ \\
\hline SLN3 & 10 & 89 & 1 & 750 & 5 & $181 \pm 3.5$ & $0.264 \pm 0.023$ & $-52.1 \pm 2.0$ \\
\hline SLN4 & 10 & 89 & 1 & 1000 & 5 & $167 \pm 8.1$ & $0.248 \pm 0.015$ & $-51.9 \pm 1.3$ \\
\hline SLN5 & 10 & 88 & 2 & 250 & 5 & $217 \pm 7.5$ & $0.136 \pm 0.022$ & $-48.5 \pm 2.4$ \\
\hline SLN6 & 10 & 88 & 2 & 500 & 5 & $198 \pm 3.5$ & $0.256 \pm 0.017$ & $-49.8 \pm 1.1$ \\
\hline SLN7 & 10 & 88 & 2 & 750 & 5 & $169 \pm 2$ & $0.168 \pm 0.024$ & $-52.8 \pm 1.7$ \\
\hline SLN8 & 10 & 88 & 2 & 1000 & 5 & $147 \pm 4.5$ & $0.126 \pm 0.015$ & $-52.5 \pm 1.5$ \\
\hline SLN9 & 10 & 87 & 3 & 250 & 5 & $223 \pm 6$ & $0.181 \pm 0.013$ & $-40.1 \pm 1.8$ \\
\hline SLN10 & 10 & 87 & 3 & 500 & 5 & $203 \pm 4.5$ & $0.261 \pm 0.023$ & $-41.2 \pm 1.4$ \\
\hline SLN11 & 10 & 87 & 3 & 750 & 5 & $171 \pm 4.1$ & $0.246 \pm 0.019$ & $-40.8 \pm 2.3$ \\
\hline SLN12 & 10 & 87 & 3 & 1000 & 5 & $158 \pm 2.08$ & $0.260 \pm 0.021$ & $-36.9 \pm 1.6$ \\
\hline
\end{tabular}

Table 2. Stability test of the SLN8 during 24 months (at $25^{\circ} \mathrm{C}$ and $20 \%$ humidity).

\begin{tabular}{llcccc}
\hline & Initial & 3 months & 6months & 12months & 24months \\
\hline Z-Average (nm) & $147 \pm 4.5$ & $145 \pm 4.1$ & $145 \pm 4.3$ & $141 \pm 4.2$ & $142 \pm 4.3$ \\
Zeta Potential (mv) & $-52.5 \pm 1.5$ & $-53.3 \pm 2.0$ & $-57.2 \pm 2.2$ & $-51.9 \pm 1.8$ & $-51.1 \pm 2.5$ \\
Pd.I & $0.126 \pm 0.015$ & $0.149 \pm 0.020$ & $0.119 \pm 0.019$ & $0.125 \pm 0.023$ & $0.131 \pm 0.021$ \\
\hline
\end{tabular}

cell to expose the inside to the receptor part and the outside stayed in contact with the donor section. The receptor fluid (isopropyl alcohol) was kept at $37 \pm 1^{\circ} \mathrm{C}$ using a water jacket during the whole experiment. Samples of $3.0 \mathrm{ml}$ were drawn before each experiment and immediately replaced with $3.0 \mathrm{ml}$ fresh isopropyl alcohol. Sampling was done at $10,20,30,60,120,180,240,300,360,420$ and $480 \mathrm{~min}$.

\section{Statistics}

Values in all experiments are represented as mean \pm SD of at least 3 independent experiments done in duplicate. In release experiments, $\mathrm{t}_{\text {max }}$ was considered significant at $p<0.05$ one-way ANOVA with Tukey post hoc.

\section{Results and Discussion \\ Preparation of simple SLN}

Tretinoin is basically insoluble in water and has high solubility in the lipid, so it was added into the lipid phase of the formulation. A high speed stirring was used to obtain a pre-emulsion before high pressure homogenization. A hot water bath was used for maintaining the pre-emulsion above the melting point. We selected cetyl palmitate as a suitable SLN lipid for tretinoin-loaded SLN and Tego Care 450 as an appropriate nonionic surfactant [23].

(Table 1) shows particle size, zeta potentials and poly dispersibility index (Pd.I) of formulations with different surfactant ranging from $1 \%$ to $3 \%$ and a fixed amount (10\%) of solid lipid at 250-1000 bar with 5 cycles of homogenization.

As depicted in (Table 1), formulation SLN8 at pressure 1000 bar with five cycles showed the best Z-average among other formulations. These data indicate that appropriate concentration of surfactant is very critical in creating stable nanoparticles. The table shows that the size of the particles depends on the production temperature, pressure, the number of homogenization cycles, the nature of the lipid matrix, surfactant blend and viscosity of lipid and aqueous phase as previously suggested [16]. The formulation SLN8 was examined for TEM, stability and release.

\section{Stability study}

The physical stability of the SLNs during prolonged storage $\left(25^{\circ} \mathrm{C}\right)$ was determined by monitoring changes in zeta potential, particle size and appearance. Formulation SLN8 showed suitable stability during the 24 months period of the study (Table 2). No obvious aggregation or phase separation was observed. Physical properties of particles showed no significant changes after 24 months.

\section{Tretinoin loading to SLNs}

The amount of $0.01 \%$ tretinoin was added to formulations SLN8 and the effect of different cycles in fixed pressure was evaluated. According to our results, the size can be reduced from $134 \mathrm{~nm}$ to $118 \mathrm{~nm}$ by increasing the number of cycles. The new formulations named Tre-SLN1 to TreSLN4 (Table 3). Consequently, the tre-SLN4 was selected as optimum formula for tretinoin-loaded SLN. As depicted in (Tables 1 and 3), formulations SLN8 and Tre-SLN4 had the most narrow size distribution and lowest particle size, compared with the other formulation.

\section{Transmission electron microscopy (TEM)}

The TEM imaging of SLN8 and Tre-SLN4 were shown in (Figure 1). The imaging revealed that the particle size was in nanometric range and they had round shape and homogeneous shading. The measured SLN particle 
Nasrollahi et al. Journal of Pharmaceutical Technology \& Drug Research 2013,

http://www.hoajonline.com/journals/pdf/2050-120X-2-13.pdf

doi: $10.7243 / 2050-120 X-2-13$

Table 3. Formulation loaded with tretinoin in different cycles and fixed pressure.

\begin{tabular}{ccccccc}
\hline Name of formulation & $\begin{array}{c}\text { HomogenizationPressure } \\
\text { (bar) }\end{array}$ & $\begin{array}{c}\text { Number of homogenization } \\
\text { cycles }\end{array}$ & Z-Average (nm) & Pd.I & Zeta Potential (mv) & EE (\%) \\
\hline Tre-SLN1 & 1000 & 3 & $134 \pm 3.05$ & $0.264 \pm 0.009$ & $-41.6 \pm 2.1$ & $93.77 \pm 0.38$ \\
Tre-SLN2 & 1000 & 5 & $128 \pm 2.6$ & $0.124 \pm 0.021$ & $-46.3 \pm 1.9$ & $91.62 \pm 0.49$ \\
Tre-SLN3 & 1000 & 7 & $124 \pm 3.6$ & $0.321 \pm 0.016$ & $-44.7 \pm 2.5$ & $91.59 \pm 0.31$ \\
Tre-SLN4 & 1000 & 9 & $118 \pm 1.5$ & $0.157 \pm 0.013$ & $-43.2 \pm 2.6$ & $90.32 \pm 0.52$ \\
\hline
\end{tabular}

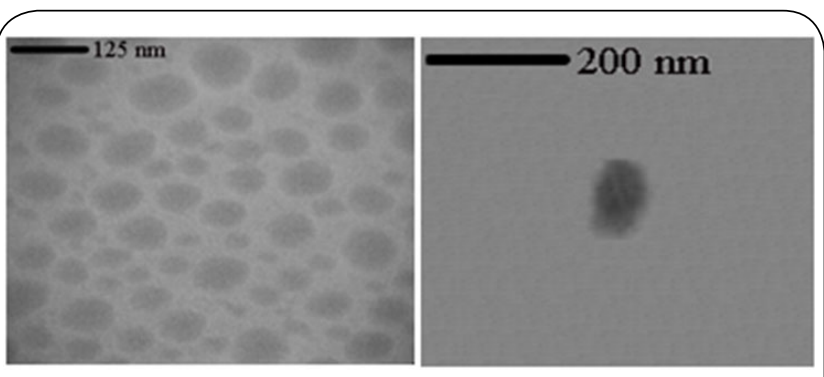

Figure 1. TEM photograph of SLN8 (left) and Tre-SLN4 (right).

Table 4. DSC results of pure lipid, surfactant, SLN8 and Tre-SLN4.

\begin{tabular}{lccccc}
\hline Name & $\begin{array}{c}\text { Onset } \\
\left({ }^{\circ} \mathbf{C}\right)\end{array}$ & $\begin{array}{c}\text { Peak } \\
\left({ }^{\circ} \mathbf{C}\right)\end{array}$ & $\begin{array}{c}\text { Endset } \\
\left({ }^{\circ} \mathbf{C}\right)\end{array}$ & $\begin{array}{c}\text { Enthalpy } \\
(\mathbf{J} / \mathbf{g})\end{array}$ & $\begin{array}{c}\text { Peak Width } \\
\left({ }^{\circ} \mathbf{C}\right)\end{array}$ \\
\hline Tego care 450 & 54 & 62 & 65 & 5.3 & 8.0 \\
$\begin{array}{l}\text { Cetyl palmitate } \\
\text { Tretinoin }\end{array}$ & 48 & 57 & 60 & 14.6 & 8.0 \\
$\begin{array}{l}\text { SLN without } \\
\text { tretinoin (SLN8) }\end{array}$ & 173 & 180 & 184 & 9.5 & 6.5 \\
$\begin{array}{l}\text { SLN containing } \\
\text { tretinoin (Tre-SLN4) }\end{array}$ & 47 & 52 & 54 & 18.7 & 5.0 \\
\hline
\end{tabular}

size by TEM images was later confirmed by particle size measurement using PCS (from 100 to $150 \mathrm{~nm}$ ).

\section{DSC studies of simple SLN and tretinoin-loaded SLN formulations}

DSC is an effective tool to detect potential drug and excipient incompatibilities as well as melting and recrystallization behavior of crystalline materials like SLNs. All the lipid, surfactant and active pharmaceutical ingredient were investigated by DSC to find a probable melting point (polymorphic transitions) of the lipid matrix, because of its loading capacity, and to evaluate the crystalline quality of included active substance [25].

As depicted in (Figure 2a) the DSC profiles of cetyl palmitate as a solid lipid component of SLN formulation showed apparent endothermic peaks at about $57^{\circ} \mathrm{C}$. We detected the melting point of Tego care 450 at $62^{\circ} \mathrm{C}$ (Figure 2b), whereas the SLN without tretinoin had an endothermic peak at $52^{\circ} \mathrm{C}$ (Figure 2c). Cetyl palmitate's peak at $57^{\circ} \mathrm{C}$ was an indication of absence of any polymorphic form. The peak of cetyl palmitate in the nano formulation had a slight shift to the lower temperature side. This could be due to a reduction in particle size and an increase in surface area, leading to a decrease in melting enthalpy $[23,26,27]$. (Figure $2 d$ ) showed the profile of the lyophilized powder of tretinoin-loaded SLN which has a single peak around $51^{\circ} \mathrm{C}$ and tretinoin in $180^{\circ} \mathrm{C}$.

The recorded DSC parameters are presented in (Table 4). The obtained results show the melting point of nanoparticles was higher than $40^{\circ} \mathrm{C}$, which is the prerequisite for topical application of lipid carriers.

The height of the endothermic peak in the thermogram of SLN-containing tretinoin (Tre-SLN4) was less than that in the SLN without tretinoin (SLN8), suggesting loss of crystallinity of the lipids and tretinoin after incorporation into SLN. The results indicate that tretinoin incorporated in SLN was not in a crystalline state but in an amorphous form. When the materials were formulated as SLN, the endothermic temperature was lower. Along with a certain effect of surfactants, the observed depressed endothermic peak for SLN may be due to the nanometric size of the particles with a huge surface area. Also DSC experiment shows that formulation Tre-SLN4 has high entrapment efficiency (EE) because of no simple tretinoin peak was seen in the thermogram of SLN-containing tretinoin.

\section{In vitro permeation studies}

(Figure 3) shows the in vitro release profile of tretinoin from nanoparticulate dispersion, cream containing SLN, Retin- $\mathrm{A}^{\oplus}$, domestic brand cream (Pars Daru) and a base cream. The drug releases from SLN and cream containing SLN were slower than from other formulations because of the slow diffusion of drug from the solid lipid nanoparticles. The percent of release increased with time until 8 hours and then declined. The prolonged drug release could be attributed to embedment of drug in the solid lipid matrix. The percentages of drug released from SLN and SLN cream were also found $90.82 \%$ and $90 \%$, respectively (Table 5). These data indicate that SLN and cream containing SLN prolonged the drug release when compared with commonly used commercial formulations. We also compared the drug release between skin and cellulose nitrate membrane. As depicted in (Figure 4), permeation profiles revealed a slow release at the beginning when cream and SLN applied on rat skin compared with those in membrane. In skin, there are both lipophilic and hydrophilic substances as well as follicular pathway which facilitate and improve penetration of nanoparticles when compared with membrane condition. We did not observe any difference in tretinoin release from SLN in the presence and absence of cream as a base carrier. 

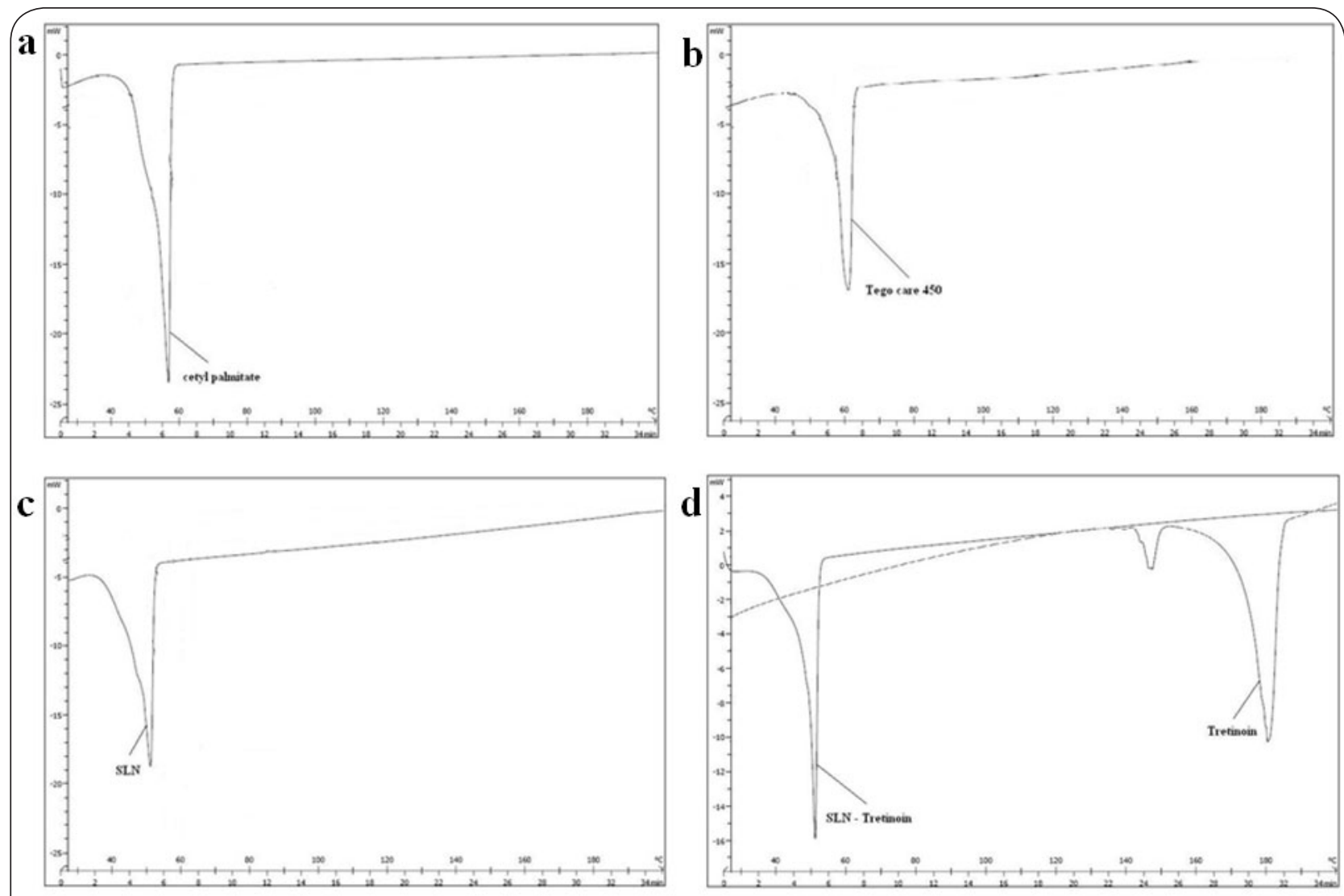

Figure 2. Differential scanning calorimetry thermogram of (a) cetyl palmitate, (b) Tego care 450, (c) simple SLN, (b) tretinoin and tretinoin-loaded SLN.

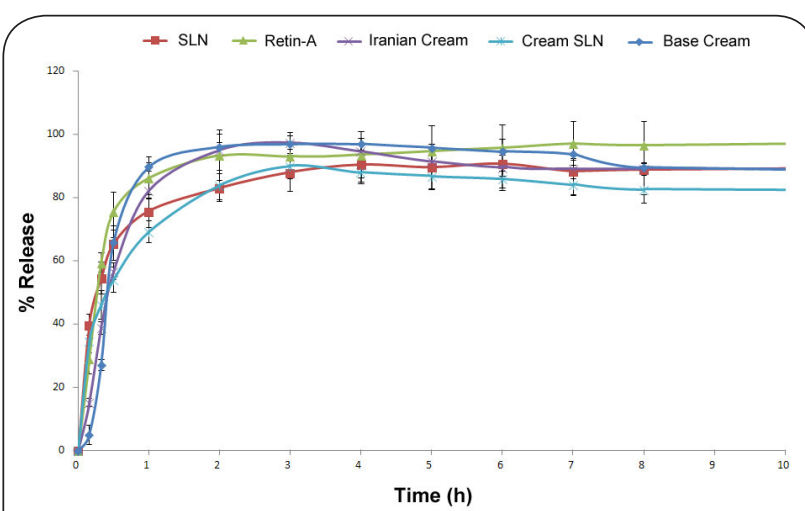

Figure 3. Percent of drug release from different formulations (experiment on cellulose nitrate membrane).

\section{Tretinoin delivery with low irritation}

Solid lipid nanoparticles (SLN) have a range of advantages such as enhanced chemicophysical stability, simplicity of scale-up and manufacturing $[\mathbf{1 7}, \mathbf{1 8}, \mathbf{2 8}]$. Moreover, their potential with small diameters is advantageous to improve the penetration of nanoparticles into skins [19,29-31] and sustained drug delivery system $[17,21]$ has been very well recognized. Because of this, exploring the potential of SLN in improving the topical delivery of tretinoin seems meaningful. One of the major disadvantages associated

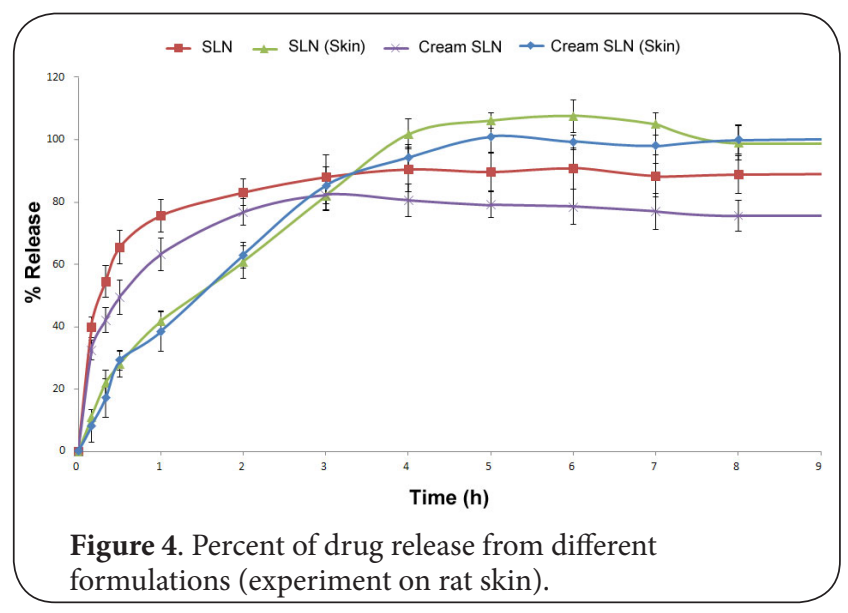

with the tretinoin therapy is skin irritation (erythema), which strongly limits its efficacy and acceptability by the patients. Preferably, the delivery system of tretinoin should be able to reduce or eliminate these erythematic side effects. On the other hand, most of the currently marketed conventional dosage forms such as creams, lotions and gels are not able to diminish the irritation caused by topical application of tretinoin. It was imagined that encapsulation of tretinoin in SLN would reduce the contact of the acidic group $(-\mathrm{COOH})$ of tretinoin with the 
Table 5. Percent of drug release from different formulations. Mean difference with $\mathbf{p}<0.05$ were considered significant using one-way ANOVA with Tukey post hoc. Asterisk represents the mean difference with $\mathbf{p}<0.05$ in comparison to conventional formulations.

\begin{tabular}{|c|c|c|c|c|c|c|}
\hline Formulation & Tretinoin Cons. & $\mathrm{C}_{\text {initial }}(\mu \mathrm{g})$ & $C_{\max }(\mu \mathrm{g})$ & $t_{\max }(\mathbf{h r} \mathbf{r})$ & $\begin{array}{c}\text { Amount of drug released } \\
\text { till } \mathbf{t}_{\max }(\mu \mathrm{g})\end{array}$ & $\begin{array}{l}\text { Percent of drug released } \\
\text { till } t_{\max }\end{array}$ \\
\hline SLN & $0.01 \%$ & 35 & 31.79 & $6^{*}$ & 31.8 & $90.82 \%$ \\
\hline Cream- SLN & $0.01 \%$ & 32 & 28.80 & $4^{*}$ & 28.9 & $90 \%$ \\
\hline Iranian cream (Pars Daru) & $0.05 \%$ & 240 & 233.89 & 3 & 233.9 & $97.45 \%$ \\
\hline Retin_A & $0.05 \%$ & 180 & 168.50 & 3 & 167.7 & $93.45 \%$ \\
\hline Base cream & $0.01 \%$ & 45 & 43.68 & 3 & 43.7 & $97.06 \%$ \\
\hline
\end{tabular}

stratum corneum and sustained delivery of tretinoin to epidermal, therefore resulting in reduced the erythematic events and improve skin tolerability [3]. In this study, the entrapment efficiency of tretinoin to SLN is higher than $90 \%$. The high compatibility between drug and lipid (cetyl palmitate) might result in the high entrapment efficiency that could be beneficial to reduce the skin irritation of tretinoin due to avoid the straight contact among tretinoin and skin surface.

\section{Conclusion}

High pressure homogenization was employed to produce SLNs. For the tretinoin-loaded SLN, cetyl palmitate and Tego Care 450 were selected as the lipid of SLN and nonionic surfactant, respectively. Formulation B4 showed the best Z-average among other SLNs. Moreover the TEM imaging of B4 showed that the particle size was in nanometric range and had round shape and homogeneous shading. SLNs showed suitable stability during the 24 month with no obvious aggregation or phase separation. When the materials were formulated as SLN, the endothermic temperature was found lower. In addition to the surfactant effects, the observed depressed endothermic peak for SLN may be due to the nanometric size of the particles with a huge surface area. The release profile of tretinoin from novel nano formulations was longer and slower when compared with that in creams with Retin-A, domestically marketed tretinoin cream (Pars Daru, Iran). Thus, SLN demonstrated remarkable advantage over marketed formulation in improving the skin tolerability of tretinoin indicating their potential in improving patient acceptance and topical delivery of tretinoin.

\section{Competing interests}

The authors declare that they have no competing interests.

\section{Authors' contributions}

SAN participated in the analysis and interpretation of the data and drafted the manuscript. AA carried out the SLN formulation and analysis experiments and participated in the release studies. ESF conceived and designed the study. All authors read and approved the final manuscript.

Publication history

Received: 18-Dec-2012 Revised: 28-Jan-2013

Re-Revised: 16-Mar-2013 Accepted: 28-Mar-2013

Published: 01-Apr-2013

\section{References}

1. Allen JG and Bloxham DP: The pharmacology and pharmacokinetics of the retinoids. Pharmacol Ther 1989, 40:1-27. | Article I PubMed

2. Zouboulis CC: Retinoids--which dermatological indications will benefit in the near future? Skin Pharmacol App/ Skin Physiol 2001 14:303-15. | Article | PubMed

3. Shah KA, Date AA, Joshi MD and Patravale VB: Solid lipid nanoparticles (SLN) of tretinoin: potential in topical delivery. Int J Pharm 2007, 345:163-71. | Article | PubMed

4. POLANO MK. Tretinoin in dermatologie. PharmWeekblad 1974: 908 909.

5. Corbeil J, Rapaport E, Richman DD and Looney DJ: Antiproliferative effect of retinoid compounds on Kaposi's sarcoma cells. J Clin Invest 1994, 93:1981-6. | Article | PubMed Abstract | PubMed Full Text

6. Nighland M, Yusuf $M$, Wisniewski S, Huddleston $K$ and Nyirady J: The effect of simulated solar UV irradiation on tretinoin in tretinoin gel microsphere $\mathbf{0 . 1 \%}$ and tretinoin gel $\mathbf{0 . 0 2 5 \%}$. Cutis 2006, 77:313-6. | Article I PubMed

7. Mandawgade SD and Patravale VB: Development of SLNs from natural lipids: application to topical delivery of tretinoin. Int J Pharm 2008, 363:132-8. | Article | PubMed

8. Masini V, Bonte F, Meybeck A and Wepierre J: Cutaneous bioavailability in hairless rats of tretinoin in liposomes or gel. $J$ Pharm Sci 1993, 82:17-21. I Article I PubMed

9. Schafer-Korting $\mathrm{M}$, Korting $\mathrm{HC}$ and Ponce-Poschl E: Liposomal tretinoin for uncomplicated acne vulgaris. Clin Investig 1994, 72:1086-91. | Article | PubMed

10. Manconi M, Valenti D, Sinico C, Lai F, Loy G and Fadda AM: Niosomes as carriers for tretinoin. II. Influence of vesicular incorporation on tretinoin photostability. Int J Pharm 2003, 260:261-72. | Article | PubMed

11. Didja Amidouche, Patricia Montassier, Marie-Christine Poelman and Dominique Duchêne: Evaluation by laser Doppler velocimetry of the attenuation of tretinoin induced skin irritation by cyclodextrin complexation. Int J Pharm 1994, 111: 111-116. | Article

12. LUCKS JS, MÜLLER RH. Medication vedicles made of solid lipid particles (solid lipid Nanospheres SLN). EP0000605497 1991.

13. Pardeike J, Hommoss A and Muller RH: Lipid nanoparticles (SLN, NLC) in cosmetic and pharmaceutical dermal products. Int J Pharm 2009, 366:170-84. | Article | PubMed

14. Liedtke S, Wissing S, Muller RH and Mader K: Influence of high pressure homogenisation equipment on nanodispersions characteristics. Int J Pharm 2000, 196:183-5. I Article I PubMed

15. Gohla SH and Dingler A: Scaling up feasibility of the production of solid lipid nanoparticles (SLN). Pharmazie 2001, 56:61-3. | PubMed

16. Saupe A, Gordon KC and Rades T: Structural investigations on nanoemulsions, solid lipid nanoparticles and nanostructured lipid carriers by cryo-field emission scanning electron microscopy and Raman spectroscopy. Int J Pharm 2006, 314:56-62. | Article | PubMed

17. Muller RH, Mader K and Gohla S: Solid lipid nanoparticles (SLN) for controlled drug delivery - a review of the state of the art. Eur J 
Nasrollahi et al. Journal of Pharmaceutical Technology \& Drug Research 2013, http://www.hoajonline.com/journals/pdf/2050-120X-2-13.pdf

Pharm Biopharm 2000, 50:161-77. | Article | PubMed

18. Mehnert W and Mader K: Solid lipid nanoparticles: production, characterization and applications. Adv Drug Deliv Rev 2001, 47:16596. | Article | PubMed

19. Chen H, Chang X, Du D, Liu W, Liu J, Weng T, Yang Y, Xu H and Yang $X$ : Podophyllotoxin-loaded solid lipid nanoparticles for epidermal targeting. J Control Release 2006, 110:296-306. | Article | PubMed

20. Munster U, Nakamura C, Haberland A, Jores K, Mehnert W, Rummel S, Schaller M, Korting HC, Zouboulis Ch C, Blume-Peytavi U and SchaferKorting M: RU 58841-myristate--prodrug development for topical treatment of acne and androgenetic alopecia. Pharmazie 2005, 60:812. | Article | PubMed

21. Iannuccelli V, Sala N, Tursilli R, Coppi G and Scalia S: Influence of liposphere preparation on butyl-methoxydibenzoylmethane photostability. Eur J Pharm Biopharm 2006, 63:140-5. | Article | PubMed

22. Jenning V, Schafer-Korting M and Gohla S: Vitamin A-loaded solid lipid nanoparticles for topical use: drug release properties. J Control Release 2000, 66:115-26. | Article | PubMed

23. Farboud ES, Nasrollahi SA and Tabbakhi Z: Novel formulation and evaluation of a Q10-loaded solid lipid nanoparticle cream: in vitro and in vivo studies. Int J Nanomedicine 2011, 6:611-7. | Article | PubMed Abstract | PubMed Full Text

24. Zhang N, Ping QN, Huang GH and Xu WF: Investigation of lectinmodified insulin liposomes as carriers for oral administration. Int J Pharm 2005, 294:247-59. | Article | PubMed

25. Souto EB, Anselmi C, Centini M and Muller RH: Preparation and characterization of $n$-dodecyl-ferulate-loaded solid lipid nanoparticles (SLN). Int J Pharm 2005, 295:261-8. | Article | PubMed

26. HUNTER RJ. Foundations of Colloid Science. Calderon Press, Oxford 1987: 228-315.

27. Freitas $\mathrm{C}$ and Muller RH: Correlation between long-term stability of solid lipid nanoparticles (SLN) and crystallinity of the lipid phase. Eur J Pharm Biopharm 1999, 47:125-32. | Article | PubMed

28. Wissing SA and Muller RH: Cosmetic applications for solid lipid nanoparticles (SLN). Int J Pharm 2003, 254:65-8. | Article | PubMed

29. Santos Maia C, Mehnert W, Schaller M, Korting HC, Gysler A, Haberland $A$ and Schafer-Korting M: Drug targeting by solid lipid nanoparticles for dermal use. J Drug Target 2002, 10:489-95. | Article I PubMed

30. Lopes LB, Ferreira DA, de Paula D, Garcia MT, Thomazini JA, Fantini $\mathrm{MC}$ and Bentley MV: Reverse hexagonal phase nanodispersion of monoolein and oleic acid for topical delivery of peptides: in vitro and in vivo skin penetration of cyclosporin A. Pharm Res 2006 23:1332-42. | Article | PubMed

31. Liu J, Hu W, Chen H, Ni Q, Xu H and Yang X: Isotretinoin-loaded solid lipid nanoparticles with skin targeting for topical delivery. Int $J$ Pharm 2007, 328:191-5. | Article | PubMed

\section{Citation:}

Nasrollahi S A, Abbasian A R and Farboud E S: In vitro comparison of simple tretinoin-cream and cream loaded with tretinoin-SLN. journal of Pharmaceutical Technology and Drug Research 2013, 2:13.

http://dx.doi.org/10.7243/2050-120X-2-13 